\title{
JONES TENDON TRANSFER MODIFICATION WITH ERWIN RAMAWAN TECHNIQUE
}

\author{
Erwin Ramawan', Teddy Heri Wardhana', Ansari Rahman ${ }^{2 *}$ \\ ${ }^{1}$ Staff of Orthopaedic and Traumatology Department, Faculty of Medicine, Universitas \\ Airlangga, Dr Soetomo General Hospital, Surabaya \\ ${ }^{2}$ Resident of Orthopaedic and Traumatology Department, Faculty of Medicine, Universitas \\ Airlangga, Dr Soetomo General Hospital, Surabaya \\ *Corresponding Author: Ansari Rahman, Resident of Orthopaedic and Traumatology \\ Department, Faculty of Medicine, Universitas Airlangga, Jl. Mayjen Prof. Dr. Moestopo 6-8, \\ Surabaya \\ E-mail: ansarirahman86@gmail.com
}

\begin{abstract}
ABSTRAK
Latar Belakang: Drop hand merupakan manifestasi klinis dari lesi nervus radialis yang menyebabkan kecacatan fungsi tangan. Jones tendon transfer merupakan salah satu modalitas terapi dalam mengatasinya dengan banyak modifikasi, akan tetapi masih belum ada kesepakatan teknik modifikasi mana yang paling baik. Salah satunya adalah dengan teknik Erwin Ramawan. Tujuan penelitian ini untuk mengetahui apakah terdapat perbedaan hasil sebelum dan sesudah dilakukan operasi tendon transfer dengan teknik Erwin Ramawan pada pasien dengan lesi nervus radialis.
\end{abstract}

Metode Penelitian: Secara retrospektif, kami mengevaluasi penderita yang mengalami lesi tipe tinggi dari n. radialis (LTR) yang dilakukan operasi tendon transfer dengan teknik Erwin Ramawan, untuk me-reroute PL ke EPL, sehingga kombinasi abduksi dan extensi thumb dapat tercapai, kemudian tendon FCR diposisikan sejajar dengan ECRB dan EDC, lalu disambungkan dengan sudut $45^{\circ}$. Selanjutnya dievaluasi secara klinis dengan menggunakan skor DASH dan dengan metode Robert G. Chouinard.

Hasil: Rerata skor DASH pada pasien LTR sebelum operasi 56,83 $\pm 16,69$ mengalami perbaikan yang signifikan $(\mathrm{p}<0,05)$ sesudah dilakukan operasi tendon transfer dengan teknik Erwin Ramawan menjadi 32,00 $\pm 11,88$. Secara fungsional, dorsifleksi dari wrist post operatif adalah 75,00 \pm 10,00 (excellent), palmarfleksi 52,00 \pm 24,65 (excellent). Untuk finger, ekstensi metacarpophalangeal mencapai 166,00 $\pm 19,49$ (good). Jarak dari fingertip ke metacarpophalangeal crease $0,10 \pm 0,22$ (good). Pada thumb, abduksi mencapai 40,00 $\pm 15,81$ (excellent), ekstensi interphalangeal 166,00 $\pm 11,44$ (good).

Kesimpulan: Berdasarkan hasil tersebut, didapatkan perbedaan klinis yang signifikan sebelum dan sesudah dilakukan tendon transfer dengan teknik Erwin Ramawan.

Kata kunci: lesi nervus radialis, tendon transfer, teknik Erwin Ramawan, skor DASH

\begin{abstract}
Background: Drop hand is a clinical manifestation of radial nerve lesion that cause hand dysfunction. Jones tendon transfer is one of the therapeutic modalities in overcoming it with many modifications, but there is still no mutual agreement for which technique is the best. One of them is the Erwin Ramawan technique. The purpose of this study was to determine the differences in results before and after tendon transfer surgery with the Erwin Ramawan technique in patients with radial nerve lesions.

Methods: Retrospectively, we evaluated patients with high-type lesions of radial nerve carried out by tendon transfer surgery using Erwin Ramawan, to reroute PL to EPL, so the thumb can do abduction and extension, then the FCR tendon is positioned parallel to the ECRB and EDC,
\end{abstract}


then connected $45^{\circ}$ direction. The outcome was evaluated using the DASH score and with the Robert G. Chouinard method.

Results: The average DASH score in patients with high-type lesions of radial nerve before surgery $56.83 \pm 16.69$ had a significant improvement $(\mathrm{p}<0.05)$ after tendon transfer surgery with Erwin Ramawan technique to $32.00 \pm 11.88$. Functionally, dorsiflexion from wrist postoperative is $75.00 \pm 10.00$ (excellent), palmarflexion $52.00 \pm 24.65$ (excellent). For finger, the metacarpophalangeal extension reaches $166.00 \pm 19.49$ (good). The distance from the fingertip to metacarpophalangeal crease is $0.10 \pm 0.22$ (good). On thumb, abduction reaches $40.00 \pm 15.81$ (excellent), interphalangeal extension $166.00 \pm 11.44$ (good).

Conclusion: Based on these results, we found significant clinical differences before and after tendon transfer with the Erwin Ramawan technique.

Keywords: radial nerve lesions, tendon transfer, Erwin Ramawan technique, DASH score

\section{PENDAHULUAN}

Nervus radialis merupakan saraf perifer yang paling sering mengalami lesi. Saraf ini berjalan di spiral groove dari humerus, sehingga lesinya paling banyak disebabkan oleh karena komplikasi fraktur pada shaft humerus (11-18\%).,

Lesi nervus radialis menyebabkan kecacatan yang berat bagi fungsi tangan normal. Setiap akan melakukan gerakan (active position), tangan akan berada pada posisi ekstensi. Pasien dengan lesi nervus radialis akan mengalami kesulitan besar dalam menggenggam obyek karena gangguan ekstensi jari dan pergelangan tangannya. Secara klinis biasanya terjadi drop hand, yang ditandai dengan ketidakmampuan untuk ekstensi jari pada sendi metacarpophalangeal (MCP), dan ketidakmampuan untuk ekstensi dan abduksi ibu jari. Secara fungsional, pasien akan terganggu sekali karena tidak dapat menggenggam obyek dengan baik, hingga berkurangnnya stabilitas dari sendi-sendi pergelangan tangan. ${ }^{3,4}$

Tendon transfer merupakan salah satu modalitas terapi dalam mengatasi lesi nervus radialis. Tendon transfer merupakan prosedur yang paling baik dan paling dapat diprediksi dalam mengembalikan fungsi tangan pada pasien lesi nervus radialis, tetapi Riordan menekankan kesuksesan prosedur ini tergantung kompetensi teknik operator dan rehabilitasi setelah operasi. ${ }^{3,4}$ Tendon yang ditransfer adalah FCU (flexor carpi ulnaris) ke EDC (extensor digitorum communis) melalui interosseous membran. Kemudian Capella pada tahun 1960 melakukan transfer tendon FCU ke EDC dan tendon FCR (flexor carpi radialis) ke EPL (ektensor pollicis longus). Pada tahun 1916, Sir Robert Jones melakukan transfer PT (pronator teres) ke ECRB (extensor carpi radialis brevis) dan ECRL (ektensor carpi radialis longus) bersamaan dengan transfer FCU ke jari tengah, jari manis dan jari 
kelingking, serta transfer FCR ke ibu jari dan jari telunjuk. Prosedur Jones transfer merupakan standar prosedur (Gambar 1), namun banyak juga laporan keberhasilan terapi dengan menggunakan teknik modifikasi dari Jones transfer ini. ${ }^{5}$
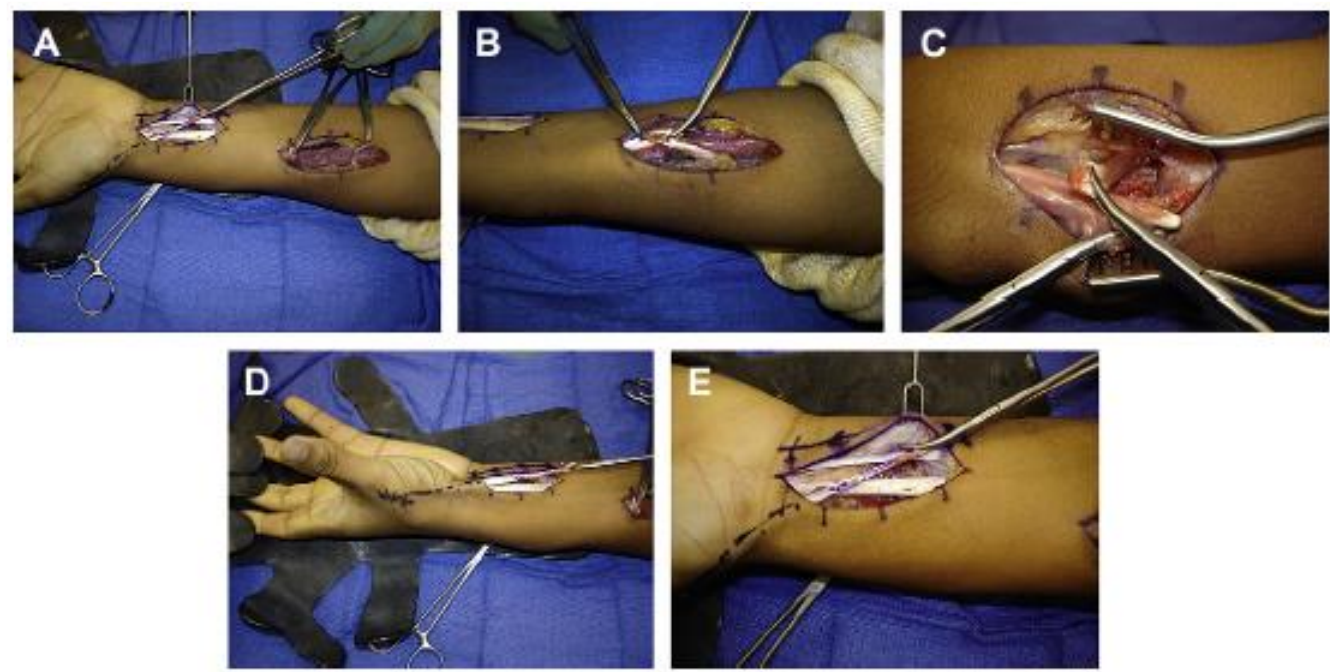

Gambar 1. Teknik Jones tendon transfer. (A) Melalui irisan volar 1/3 distal lengan atas, PL dan FCR diisolasi dan EPL tendon yang telah ditranseksi dipindahkan melalui irisan ini. Melalui irisan terpisah pada aspek radial pertegahan lengan atas, PT dilepaskan dari radius dan ECRB ditranseksikan pada musculotendinous junction nya. (B) PT awalnya dijahitkan ke ECRB dengan wrist dalam extensi penuh dan PT dalam ketegangan istirahat. (C) FCR dilewatkan di aspek radial tendon-tendon flexor dan nervus medianus melalui jendela di membrana interosseous dan dijahitkan dalam ketegangan istirahat ke tendon EDC dengan posisi jari jari extensi penuh pada sendi MCP. (D,E) Dengan ibu jari dalam abduksi radial penuh dan extensi, tendon EPL yang telah dipindahkan dijahitkan ke tendon PL dalam ketegangan istirahat.

Meskipun banyak sekali kombinasi tendon transfer pada kasus lesi nervus radialis, akan tetapi masih belum ada kesepakatan teknik kombinasi mana yang paling baik. Pada kasus pasien LTR yang dipresentasikan pada Konferensi Kerja PABOI ke XII di Tangerang pada bulan November 2015, ada dua kombinasi tendon transfer yang digunakan oleh penulis, yaitu PL di reroute ke EPL, dan FCR ke ECRB dan EDC. Penulis menggunakan teknik ini karena beberapa alasan berikut; 1) posisi FCR di sisi radial memungkinkan searah dengan normal aksis dari pergerakan wrist yaitu dari "dorso-radial" ke arah "volarulnar", sehingga cocok untuk ditransferkan ke ECRB, 2) FCR ditransferkan ke ECRB juga sekaligus ke EDC dikarenakan kedua tendon-tendon ini letaknya bersebelahan satu sama lain, 3) FCR sebagai donor cukup panjang untuk mencakup ke enam tendon ini, 4) pergerakan utama FCR sebagai fungsi 


\section{Artikel Penelitian}

Vol 8 No. 2, Oktober 2019

ISSN 2460-8742

http://journal.unair.ac.id/ORTHO@journal-orthopaedi-and-traumatology-surabaya-media-104.html

fleksi radial-deviasi (yang bagi pasien

pemilihan tendon donor FCR dan sudah terbiasa dan termemori dalam mempertahankan FCU menjadikan fungsi otaknya) berdekatan dengan arah aksis wrist ekstensi (dorso-radial) sehingga hummering masih bisa dilakukan oleh pasien. ${ }^{6}$

memudahkan dalam melatih dan bisa didapatkan hasil yang fungsional, 5)
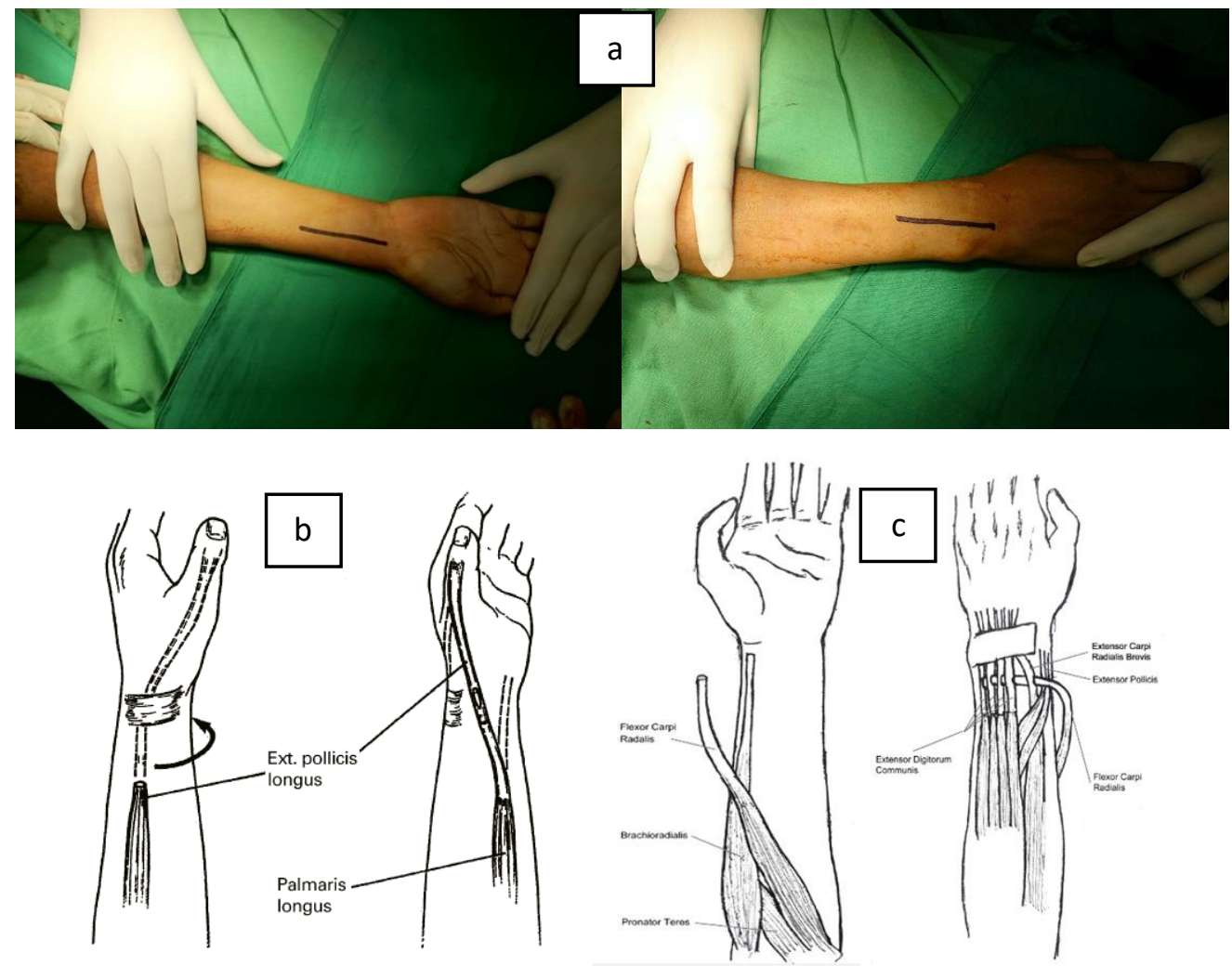

Gambar 2. Teknik operasi modifikasi dengan teknik Erwin Ramawan ${ }^{6}$

Tendon transfer teknik Erwin Ramawan (Gambar 2), secara umum terdiri atas:

1. a, kombinasi volar dan dorsal insisi untuk transfer. Insisi kecil transvers pada dorsal MCP joint thumb dan volar wrist digunakan untuk me-reroute EPL.

2. b, Transfer PL untuk reroute ke EPL, sehingga kombinasi abduksi dan extensi thumb dapat tercapai.

3. c, Tendon FCR disiapkan dan ditempatkan sejajar mungkin dengan posisi ECRB dan EDC, lalu disambungkan dengan sudut $45^{\circ}$.

\section{METODOLOGI PENELITIAN}

Objek dalam penelitian ini adalah semua penderita LTR yang dilakukan operasi tendon transfer dengan menggunakan teknik modifikasi Erwin Ramawan di RSUD Dr Soetomo, Surabaya dan RS Siloam, Surabaya mulai 2014 sampai 
2017. Alur penelitian ditunjukkan oleh

Gambar 3 berikut.

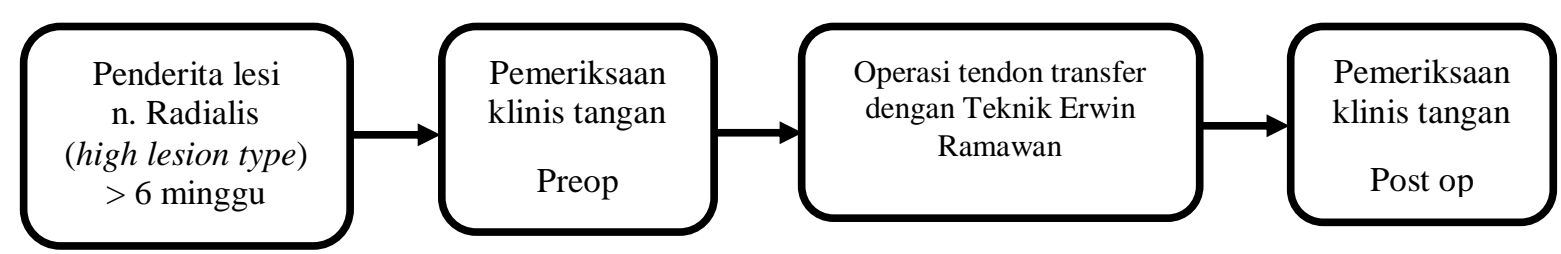

Gambar 3. Alur penelitian

Diadakan penelusuran data melalui rekam medik penderita, dicatat mengenai identitas penderita, penyebab lesi, waktu terjadinya lesi serta diagnosa. Kemudian dilakuan penilaian klinis dengan menggunakan DASH score. Adapun pencatatan dan pengukuran data pascaoperasi sesuai dengan tabel 1 , meliputi fungsi DF: dorsiflexion. PF: palmar flexion. MP Ext: Metacarpophalangeal joint ext. FT-MPC: finger tip to mid palmar crease, ABD: abduction IP Ext: interphalangeal joint extension.

Tabel 1. Evaluasi Klinis Pascaoperasi Tendon Transfer dari Robert G. Chuinard ${ }^{5}$

\begin{tabular}{llccccc}
\hline & \multicolumn{2}{c}{ Wrist } & \multicolumn{2}{c}{ Finger } & \multicolumn{2}{c}{ Thumb } \\
\hline & DF & PF & Ext MP & FT-MPC & ABD & Ext IP \\
\hline Excellent & $>50$ & $>30$ & $>170$ & 0 & $>40$ & $>180$ \\
Good & 25 to 50 & 10 to 30 & 135 to 170 & 0 to $1 / 21 \mathrm{n}$ & 30 to 40 & 165 to 180 \\
Fair & $<25$ & $<10$ & $<155$ & $>1 / 2$ in & $<30$ & $<165$ \\
Poor & No improvement & & & & & \\
\hline
\end{tabular}

Keterangan:

DF: Dorsofleksi wrist

PF: Palmarfleksi wrist

Ext MP: Ekstensi metacarpophalangeal

Data hasil pemeriksaan disajikan secara deskriptif dan dilanjutkan dengan uji hipotesis. Normalitas data hasil pemeriksaan diuji dengan uji Kolmogorov-smirnov. Uji komparasi data numerikal dengan menggunakan Paired T-test jika data
FT-MPC: Fingertip-Metacarpophalangeal crease

Abd: Abduksi

Ext IP: Ekstensi interphalangeal 


\section{HASIL DAN PEMBAHASAN}

Seluruh subjek penelitian adalah lakilaki. Usia subjek penelitian berkisar antara 17 tahun hingga 56 tahun dengan rerata usia $28,60 \pm 15,60$. Hal tersebut sesuai dengan beberapa literatur yang menyatakan bahwa lesi nervus radialis sehubungan dengan fraktur shaft humerus terjadi sekitar 11-18\%, dan banyak terjadi pada pria muda.

Subjek penelitian adalah pasien dengan LTR dan secara keseluruhan disertai dengan fraktur humerus. LTR sering terjadi karena faktor letak anatomisnya yang terfiksir dan dekat dengan tulang humerus pada sepertiga tengah. ${ }^{2,7}$ Banyak studi lain menemukan bahwa insidensi LTR lebih tinggi sebagai komplikasi pada fraktur humerus sepertiga tengah, yang menunjukkan bahwa di sini kedekatan saraf ke tulang adalah faktor risiko yang lebih besar. ${ }^{8}$ Carlan et al menemukan bahwa nervus radialis beresiko lesi di sepanjang shaft humerus pada dua lokasi. Yang pertama adalah sepanjang $6,3 \mathrm{~cm} \pm 1,7 \mathrm{~cm}$ dari tuberositas deltoid pada midshaft posterior. Yang kedua adalah pada sisi lateral humerus sepertiga distal, antara 10,9 $\mathrm{cm} \pm 1,5 \mathrm{~cm}$ proksimal dari epikondilus lateral. ${ }^{8}$

Onset dari kejadian lesi hingga dilakukan operasi tendon transfer berkisar antara 2 tahun hingga 3 tahun dengan rerata
2,40 $\pm 0,55$ tahun. Waktu dilakukannya tendon transfer masih kontroversial. Ada dua pilihan, apakah dikerjakan awal bersamaan dengan repair dari nervus radialis atau yang lebih konvensional, yakni menunda tendon transer hingga terjadi kegagalan reinervasi dari musculus brachioradialis dan ECRL. Makin proximal lesi nervus yang terjadi, makin kecil kemungkinan reinervasinya., ${ }^{9,10}$ Apabila saraf masih intak, beberapa ahli bedah menyarankan untuk observasi selama 3 bulan sambil menunggu penyembuhan spontan.

Sebelum menjalani operasi tendon transfer, seluruh pasien mengalami keluhan yang sama berupa wrist drop/drop hand. Tanda klinis dari lesi nervus radialis adalah wrist drop. Wrist drop terjadi selain karena gravitasi, juga diakibatkan oleh tonus flexor wrist yang mengalahkan extensor yang kehilangan fungsinya, sehingga tangan tertarik pada posisi palmarflexi. Wrist dapat secara pasif ditempatkan ke posisi dorsoflexi, namun pasien tidak mampu menahan posisi tersebut, sehingga tangan tidak dapat mempertahankan posisi fungsional. Selain itu, hilangnya fungsi ekstensi jari-jari dan ibu jari, menyebabkan hilangnya kemampuan dari pasien untuk membuka tangan sebelum memulai gerakan menggenggam, sehingga sangat sulit bagi pasien untuk melakukan kegiatan yang 


\section{Artikel Penelitian}

Vol 8 No. 2, Oktober 2019

ISSN 2460-8742

http://journal.unair.ac.id/ORTHO@journal-orthopaedi-and-traumatology-surabaya-media-104.html

membutuhkan ketangkasan manual yang terkoordinasi.

Dari penelitian ini, didapatkan skor DASH yang membaik pada pasien LTR yang dilakukan operasi tendon transfer dengan teknik Erwin Ramawan. Rerata skor DASH pada pasien lesi nervus radialis sebelum operasi $56,83 \pm 16,69$ mengalami perbaikan yang signifikan $(\mathrm{p}<0,05)$ sesudah dilakukan operasi tendon transfer dengan teknik Erwin Ramawan menjadi 32,00 \pm 11,88 dan dapat dilihat lebih jelas pada Gambar 4.

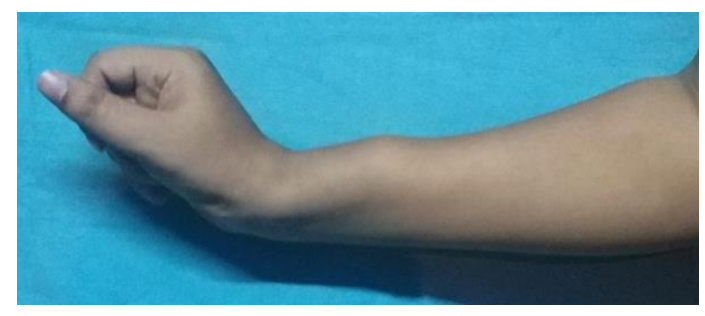

Gambar 5. Dorsofleksi wrist post operasi

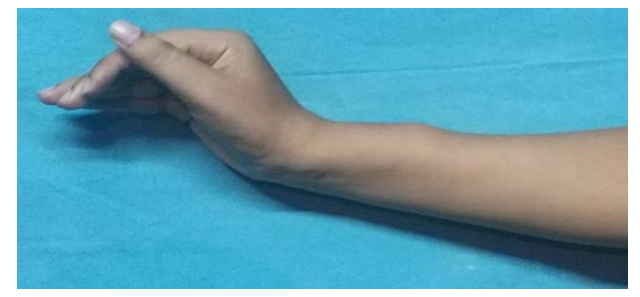

Gambar 7. Ekstensi metacarpophalangeal post operasi

Berdasarkan tabel Robert G. Chouinard, dilakukan evaluasi fungsi berdasarkan range of motion dari pergerakan

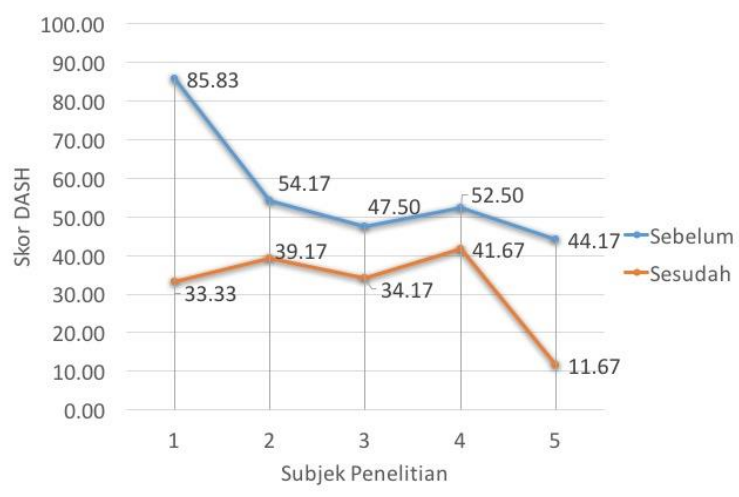

Gambar 4. Grafik perbandingan DASH score sebelum dan sesudah dilakukan operasi tendon transfer

Berikut evaluasi klinis pasien dengan lesi nervus radialis yang telah dilakukan operasi tendon transfer dengan teknik Erwin Ramawan diperlihatkan pada Gambar 5-8.

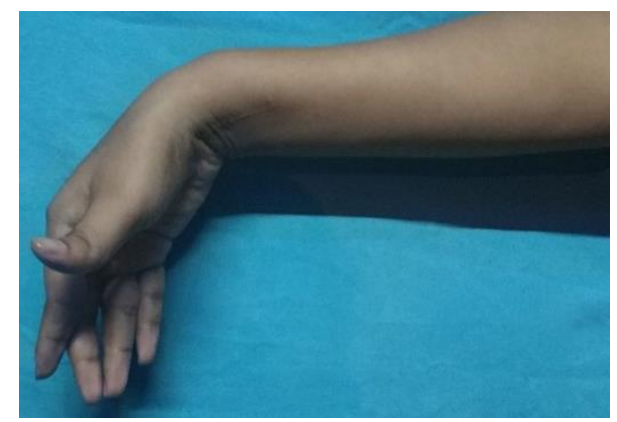

Gambar 6. Palmarfleksi wrist post operasi

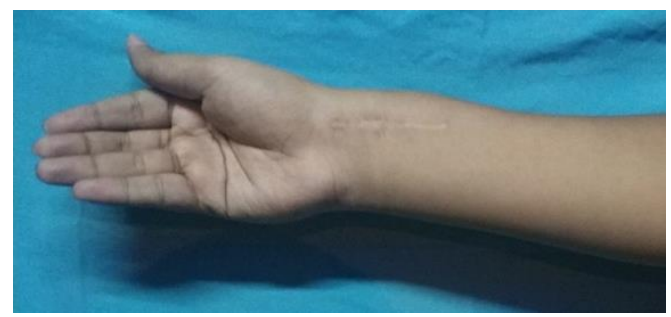

Gambar 8. Abduksi thumb post operasi

wrist, thumb dan finger. Selengkapnya dijabarkan pada Tabel 2 berikut ini. 
Tabel 2. Evaluasi Klinis Pascaoperasi Tendon Transfer dengan Teknik Erwin Ramawan dari Robert G. Chuinard

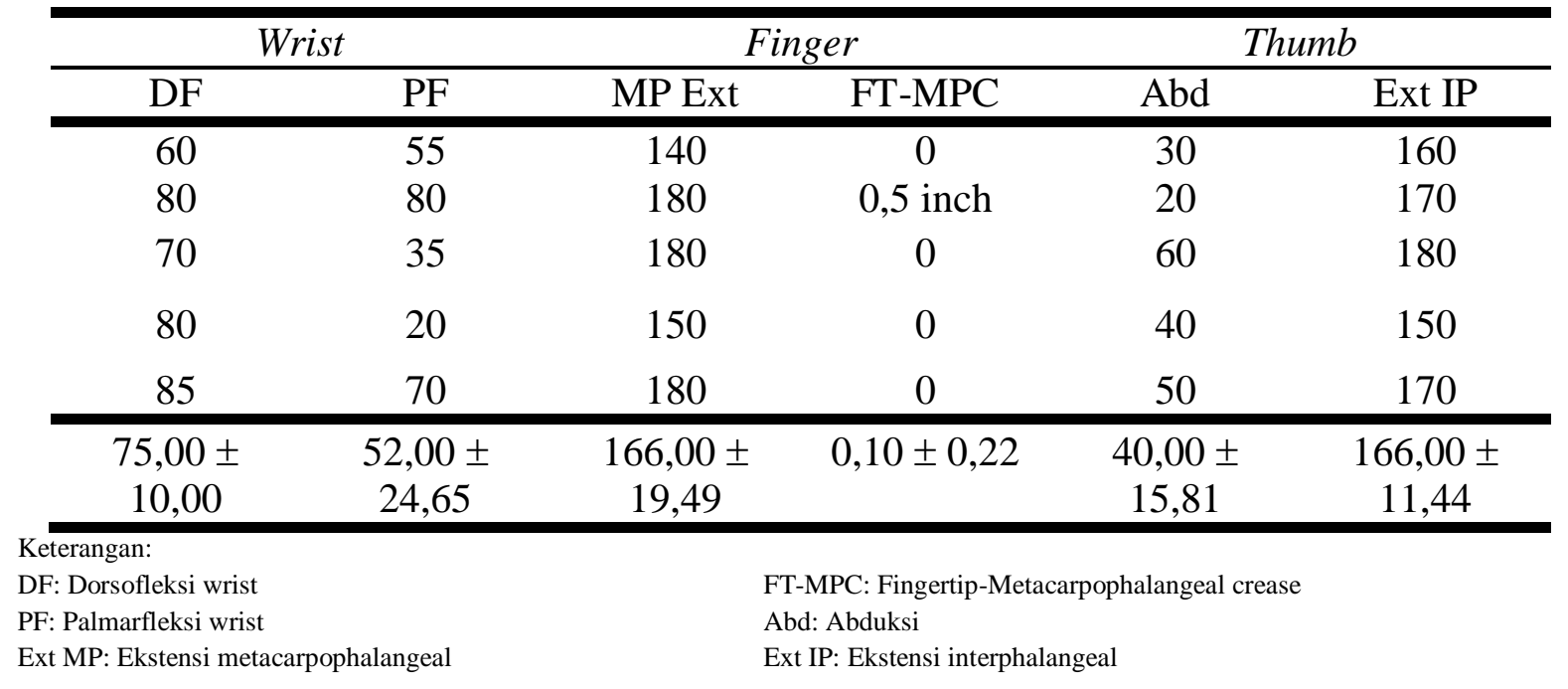

Pada Tabel 2, didapatkan dorsofleksi dari wrist pascaoperasi yang excellent dengan rerata $75,00 \pm 10,00$. Selain itu, didapatkan palmarfleksi wrist post operatif yang juga excellent dengan rerata $52,00 \pm$ 24,65. Untuk gerakan dari finger, didapatkan hasil yang baik (good) dari ekstensi metacarpophalangeal pascaoperasi dengan rerata $166,00 \pm 19,49$. Pada posisi menggenggam, didapatkan jarak dari fingertip ke metacarpophalangeal crease yang juga baik (good) dengan rerata $0,10 \pm$ 0,22. Pada thumb, pascaoperasi didapatkan gerakan abduksi yang baik (good) hingga excellent dengan rerata $40,00 \pm 15,81$ serta gerakan ekstensi interphalangeal yang baik (good) 166,00 $\pm 11,44$.

Teknik Erwin Ramawan digunakan karena beberapa alasan di antaranya; 1) posisi FCR di sisi radial memungkinkan searah dengan normal aksis dari pergerakan wrist yaitu dari "dorso-radial" ke arah "volar-ulnar", sehingga cocok untuk ditransferkan ke ECRB, 2) FCR ditransferkan ke ECRB juga sekaligus ke EDC dikarenakan kedua tendon-tendon ini letaknya bersebelahan satu sama lain, 3) FCR sebagai donor cukup panjang untuk mencakup ke enam tendon ini, 4) pergerakan utama FCR sebagai fungsi flexi radialdeviasi (yang bagi pasien sudah terbiasa dan termemori dalam otaknya) berdekatan dengan arah aksis wrist ekstensi (dorsoradial) sehingga memudahkan dalam melatih dan bisa didapatkan hasil yang fungsional, 5) pemilihan tendon donor FCR dan mempertahankan FCU menjadikan fungsi hummering masih bisa dilakukan oleh pasien. Alhasil didapatkan range of motion dari wrist, finger dan thumb dengan hasil yang baik (good) hingga excellent. Hal ini 
juga didukung oleh evaluasi klinis dengan menggunakan skor DASH menunjukkan perbaikan yang bermakna pada subjek penelitian.

\section{KESIMPULAN DAN SARAN}

Dari penelitian ini, kita dapat menyimpulan bahwa terdapat perbedaan klinis yang signifikan sebelum dan sesudah prosedur tendon transfer pada pasien yang dilakukan operasi tendon transer dengan teknik Erwin Ramawan. Oleh karena itu, tendon transfer dengan menggunakan teknik Erwin Ramawan dapat dijadikan pedoman dalam pilihan prosedur tendon transfer pada pasien dengan lesi nervus radialis.

Di masa mendatang, kami menyarankan agar pendataan pasien dengan kasus lesi nervus radialis sebaiknya dibuat secara lengkap dan evaluasi dilakukan secara berkala. Selain itu, diharapkan dapat dilakukan evaluasi klinis dengan perbandingan menggunakan teknik tendon transfer yang lain.

\section{REFERENSI}

1. Walker M, Palumbo B, Badman B, Brooks J, Gelderen JV, Mighell M. Humeral shaft fractures: A review. Journal of Shoulder and Elbow Surgery. 2011;20(5):833-844.

2. Ricci FPFM, Barbosa RI, Elui VMC, Barbieri CH, Mazzer N, Fonseca MCR. Radial nerve injury associated with humeral shaft fracture: a retrospective study. Acta Ortopedica Brasileira. 2015;23(1):19-21.

3. Davis, T. (2011) 'Principles of Tendon Transfers of Median Radial, and Ulnar Nerves', in Wolfe, S. et al. (eds) Green's Operative Hand Surgery. 7th ed. Philadelphia: Elsevier, pp. 1062-1078.

4. Suzuki T, Kunishi T, Kakizaki J, Iwakura N, Takahashi J, Kuniyoshi K. Wrist extension strength required for power grip: a study using a radial nerve block model. Journal of Hand Surgery. 2012;37(5):432-435.

5. Chuinard RG, Boyes JH, Stark HH, Ashworth CR. Tendon transfers for radial nerve palsy: Use of superficialis tendons for digital extension. Journal of Hand Surgery. 1978;3(6):560-570.

6. Ramawan E. Personal communication. 2017.

7. Carroll EA, Schweppe M, Langfitt M, Miller AN, Halvorson JJ. Management of Humeral Shaft Fractures. Journal of the American Academy of Orthopaedic Surgeons. 2012;20(7):423-433.

8. Gerwin M, Hotchkiss R. and Weiland A. Alternative operative exposures of the posterior aspect of the humeral diaphysis with reference to the radial nerve. The Journal of Bone \& Joint Surgery [Am]. 1996; 78(11):16901695.

9. Ratner JA, Peljovich A and Kozin, S. H. Update on Tendon Transfers for Peripheral Nerve Injuries. Journal of Hand Surgery. 2010;35(8):1371-1381.

10. Jones NF and Machado GR. Tendon Transfers for Radial, Median, and Ulnar Nerve Injuries: Current Surgical Techniques. Clinics in Plastic Surgery. 2011;38(4):621-642. 